\section{INTRAMUSCULAR DELTOID INJECTION ABSCESS IN PATIENTS PRESENTED TO A TERTIARY CARE HOSPITAL IN KHYBER PAKHTUNKHWA

\author{
Mubashira Ahmad ${ }^{\prime \otimes}$, Munir Ahmad', Sikandar Hayat', \\ Fakhar-e-Alam', ljaz Ahmad'
}

\begin{abstract}
OBJECTIVES: To find out the reasons of deltoid injection abscess in female patients and disseminate awareness in our population.

METHODS: This descriptive cross-sectional study was conducted in the female outpatient Department of Surgery at Khyber Teaching Hospital, Peshawar, Pakistan from April 2017 to December 2017. All female patients with age more than 14 years who presented with deltoid injection abscesses on either arm were included and patients with diabetes, bleeding disorders, major debilitating disorders or immune-compromised conditions were excluded. All patients were interviewed regarding the intramuscular injection technique and data was collected on a structured proforma and analyzed on SPSS 20.
\end{abstract}

RESULTS: A total of fifty female patients were studied in which $56 \%$ were in the age group of $26-45$ years with mean age $35.5 \pm 12.93$ years, $14(28 \%)$ qualified and $36(72 \%)$ non-qualified personnel administered the injection. It was injected over the sleeve in $4 \mathrm{I}(82 \%)$ patients while in only $9(18 \%)$ patients the arm was exposed properly. The reasons for insignificant exposure came out to be social reasons in $9(18 \%)$, time deficiency in $9(18 \%)$, improper trained personnel in $19(38 \%)$, tight sleeves in $4(8 \%)$ patients. In $9(18 \%)$ patients aseptic measures were used while in $4 \mathrm{I}(82 \%)$ patients no aseptic measures were taken.

CONCLUSION: Most of the patients got abscess after intramuscular injection due to lack of awareness, improperly trained personnel and simple avoidable reasons, which can rectified for benefit of the community.

KEY WORDS: Injection (MeSH); Abscess (MeSH); Deltoid Muscle (MeSH); Local Practitioner (Non-MeSH).

THIS ARTICLE MAY BE CITED AS: Ahmad M, Ahmad M, Hayat S, Fakhar-e-Alam, Ahmad I. Intramuscular deltoid injection abscess in patients presented to a tertiary care hospital in Khyber Pakhtunkhwa. Khyber Med Univ J 2018;10(3): 150-3.

\section{INTRODUCTION}

$\Delta$ ccording to the World Health Organization (WHO), intramuscular injection is a parenteral administration of drugs through a puncture in the skin with a needle on a large muscle of the body for curative or prophylactic purposes.' One of the most important step of medical treatment and practical intervention for local techniques is the administration of intramuscular injection (IMI). The most preferable sites for IMI are deltoid and gluteal regions due to the excessive muscle bulk and less fats.
Mostly injections are given for therapeutic measures, since only $5 \%$ of all injections are for vaccination. In developing countries the injectables are used unnecessarily as a replacement for oral medications without knowing the potential complications they can cause. ${ }^{2}$

A skilled injection technique results in less pain and prevents many avoidable complications $^{3}$ for example fibrosis, muscle contracture, nerve injury, formation of abscesses at the injection site and gangrene etc. ${ }^{4}$

The first complication of the hypodermic
I Department of Surgery, Medical Teaching Institute Khyber Teaching Hospital, Peshawar, Pakistan Email $^{凶}:$ mubashiraahmad7@gmail.com Contact \# : +92-333-9292667

Date Submitted: January I, 2018

Date Revised: September 22, 2018

Date Accepted: September 24, 2018

injection of drugs was reported by Dr. Charles Hunter in 1865. At the time of his report, there was no sterilization of medications, syringes or needles. Unfortunately, even today the incidence of developing an IMI complication ranges from $0.4-19.3 \%$ of patients. ${ }^{5}$

Infection can be a potential complication of any injection. The causes narrated can be an incorrect site, repeated injections at one site, causing skin and surrounding tissues to be damaged, developing local ischemia and necrosis therefore, becoming susceptible to infections. ${ }^{6}$ Once an infection starts, it converts into an abscess, which is treated surgically via incision and drainage. ${ }^{7}$

In developing countries, abscesses are the result of injection involving unsterile measures including the use of contaminated needles and dirty clothes, which is not the case in developed countries. ${ }^{8}$ Therefore, there is a need for a system to follow established protocols for the administration of IMI both safely and effectively.

The purpose of this study is to highlight the reasons of deltoid injection abscesses in female patients due to various faults as a result of social restraints. It is to make our healthcare providers realize that the skilled administration of a drug by intramuscular injection needs improvement and awareness not only among the practitioners but also among the local population. It is about instilling awareness in the best interest of society to eliminate avoidable complications and indirectly the unnecessary burden on medical institutions.

\section{METHODS}

The descriptive study was conducted in the female outpatient department of Surgery at Khyber Teaching Hospital, Peshawar, Pakistan for a period of eight months i.e. April 2017 to December 2017. All female patients with age more 
TABLE I: AGE WISE DISTRIBUTION OF THE STUDY SAMPLE

\begin{tabular}{|c|c|c|}
\hline Age groups (years) & Frequency & Percentage \\
\hline $16-25$ & 13 & 26.0 \\
\hline $26-45$ & 28 & 56.0 \\
\hline $46-70$ & 9 & 18.0 \\
\hline Total & 50 & 100.0 \\
\hline
\end{tabular}

than 14 years who presented with deltoid injection abscess on either arm were included and patients with diabetes, bleeding disorders, major debilitating disorders or immune-compromised conditions were excluded after taking informed consent in the study.

All patients were immediately worked up as a day case with detailed history and clinical examination. All patients were interviewed regarding the Intramuscular injection technique and the parameters studied were broad qualification of the personnel injecting the intramuscular injection, the exposure of respective area, the reason for insignificant exposure and the aseptic measures taken or not. Data was collected on a set proforma and analyzed on SPSS v20. Frequency and percentages were calculated for categorical data like etiology. Mean and standard deviations (SD) were measured for numerical variables like age. All results were presented in the form of tables.

\section{RESULTS}

A total of 50 female patients with deltoid injection abscess were studied in which $56 \%$ were in the age group of $26-45$ years with mean age $35.5 \pm 12.93$ years (Table I). Intramuscular injections were administered by qualified personnel in 14 (28\%) cases and by non-qualified personnel in $36(72 \%)$ cases. It was injected over the sleeve in $4 \mathrm{I}(82 \%)$ patients while in only $9(18 \%)$ patients the arm was exposed properly.

The reasons for insignificant exposure were shown in Table II. In 9 (18\%) patients aseptic measures were used while in 4 I (82\%) patients no aseptic measures were taken.

\section{DISCUSSION}

Injection abscess is an iatrogenic infection that can occur as an isolated case or as a cluster outbreak. Dr. Hunter, whose patients developed the first reported complication of IMI, said "If the site of the injection was continuously varied and the puncture was performed carefully and quickly, there was no fear of abscess or diffuse inflammation"." The procedure can lead to numerous and surprising complications. Terry Treadwell concluded that inadequate training in proper injection technique is responsible; however, the true etiology remains an unresolved dilemma. ${ }^{5}$

The cause may be contaminated injectables or inadequate sterilization protocols, pathogens such as pseudomonas, klebsiella, E. coli and S. aureus are the usual causative agents. ${ }^{10}$ The most common complications noted after IMI are abscesses, pain, bleeding from the injection site, hematoma, recurrent abscess, tissue necrosis, scar formation and fibrous myopathy." In addition, these unsafe and unhygienic techniques can lead to a number of infections, particularly hepatitis B and C and HIV.'

Abscesses due to injections are the nodules of liquefied fat and muscle resulting due to necrosis of the affected tissues. Muscle necrosis can occur after any IMI no matter what medication is used. The amount, speed and toxicity of the injected drug will influence the size of

The selection of the site and the appropriate place for IMI is immensely important. According to Waleem SSU, et al. $64.2 \%$ of the practitioners were not sure about the correct site of injection in the deltoid muscle. In another study, it is recommended to avoid the deltoid region whenever possible since it is a small area available for safe IMI. The the lesion. ${ }^{13}$ needle should enter at 90 degrees to the skin punctured site and repeated IMI should be avoided. ${ }^{14}$

In our study, the etiology of the deltoid injection abscess in female patients in our settings is eagerly awaited. We have added that ignorance is not always a blessing, since not only practitioners but also our patients and their attendants mostly males are of the opinion that they can escape complications every time since $18 \%$ of female patients were not allowed to expose their arms before IMI. The IMI was administered by $72 \%$ of non-qualified personnel and was injected over the sleeve in a horrendous $82 \%$ of the patients.

According to a study, it was observed that $5.5 \%$ of the test subjects admitted to have been injected through the clothes, whereas $11.9 \%$ had the habit of cleaning the needle with a cotton swab before the injection. Injecting through the clothing can lead to the introduction of dust, cloth fiber and other infectious organisms at the site of injection. ${ }^{4}$

In our study we have highlighted the reason for inadequate exposure in female patients of our setting. Although the lack of time, improperly trained staff, tight sleeves were some of the reasons for inappropriate exposure. In 18\% of patients there were social reasons in which male attendants did not allow their patients to expose their arms to male practitioners and therefore; aseptic measures were not taken in $82 \%$ of patients.

A study by Akbar Z, et al. shows deltoid abscess in $61.54 \%$ male and $38.46 \%$ female patients doesn't consider social reasons in female patients. ${ }^{8}$

There may be other reasons for abscesses by deltoid injection as shown in the literature but here a possible avoidable cause for infections through IMI is emphasized to eliminate the

\section{TABLE II: REASONS OF IMPROPER EXPOSURE OF ARM FOR INTRAMUSCULAR INJECTION}

\begin{tabular}{|l|c|c|}
\hline \multicolumn{1}{|c|}{ Reasons } & Frequency & Percentage \\
\hline Improper trained personnel & 19 & 38.0 \\
\hline Social reasons & 9 & 18.0 \\
\hline Time deficiency & 9 & 18.0 \\
\hline Properly exposed arms & 9 & 18.0 \\
\hline Tight sleeves & 4 & 8.0 \\
\hline \multicolumn{1}{|c|}{ Total } & 50 & 100.0 \\
\hline
\end{tabular}




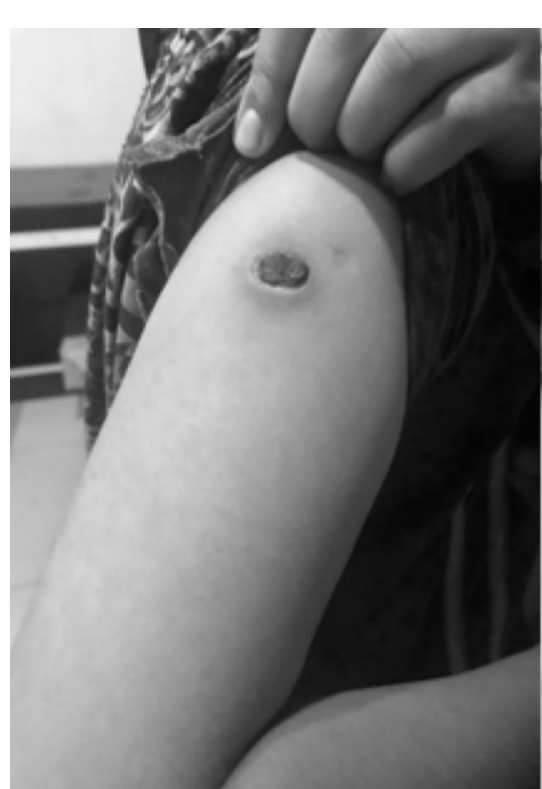

IA

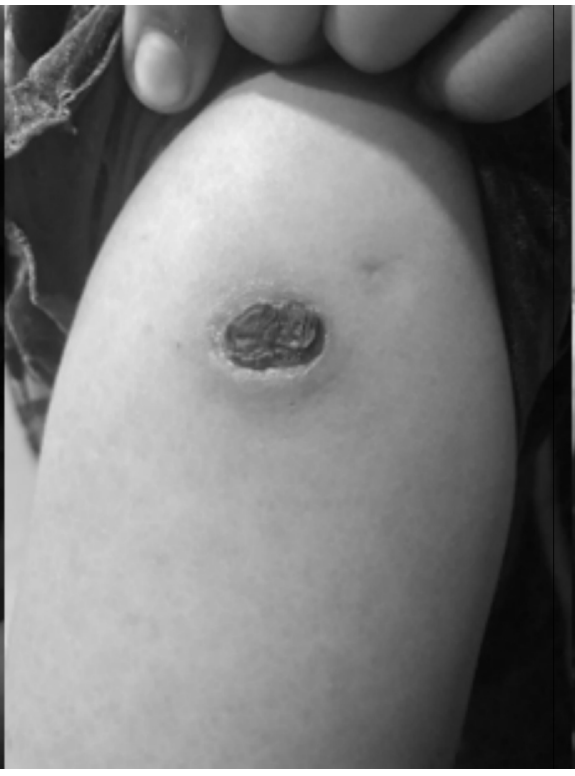

IB

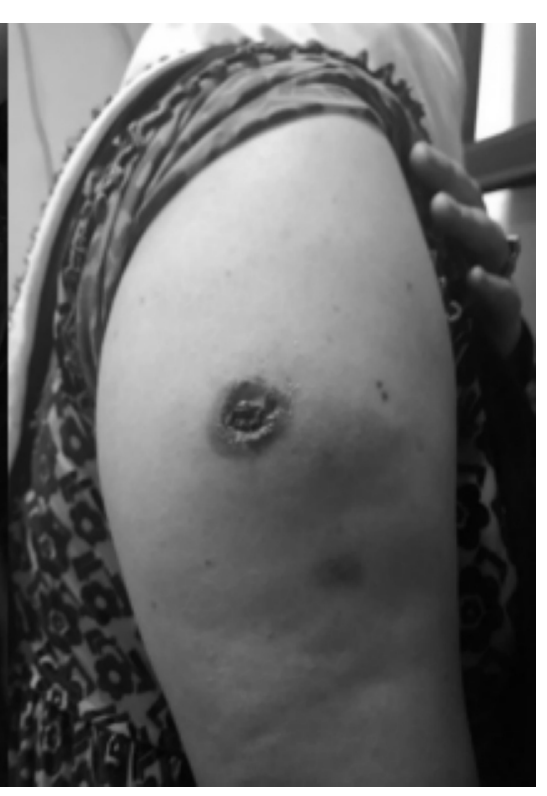

IC

Figure I: Intramuscular injection deltoid abscesses of patients under study

frequency of abscesses by deltoid injections due to inappropriate exposure in a male dominating society.

It is to minimize the unnecessary burden on medical funds through awareness rising. It has been cited in literature that unsafe IMI techniques have led to millions of dollars in cost each year. ${ }^{15}$

As cited in the literature, infections can be minimized by thoroughly cleansing the skin after adequate exposure, use of disposable needles, single dose medications, adequate needle size and length, multiple sites if repeated and retracting the plunger before injecting.

The limitations of our study are that we conducted this study on female patients only. The main reason for not including male patients is that the author is examining only female patients in female outpatient Department of Surgery. So the present study cannot be generalized to male patients too. Few of the other limitations of the study include other potential causes of IMI abscesses such as personal hygiene, type of drug administered, duration and number of injections, single syringe used on multiple patients, length and guage of needle used, proper site for administration used, type of bacteria, depth and extent as well as recovery related to age. These causes were not studied as the study was conducted on patients rather than practitioners who were not aware of the technical issues. Further research can be done on the mentioned potential technical causes to minimize the complications.

\section{CONCLUSION}

Most of the patients got abscess after intramuscular injection due to lack of awareness, improperly trained personnel and simple avoidable reasons, which can rectified for benefit of the community.

\section{RECOMMENDATION}

In addition to the proper training to health care providers, awareness among the practitioners and local population regarding appropriate exposure before intramuscular injection must be commonly practiced that can avoid unnecessary complications.

\section{REFERENCES}

I. World Health Organization (WHO). Safety of injections: A brief background. WHO, Geneva. Fact Sheet no. 23I, 1999.

2. Lala MK, Lala KR. Review of injection practice. Indian J Practical Pediatr 200I;3:72-5.

3. Hunter J. Intramuscular injection techniques. Nurs Stand 2008;22(24):35-40. DOI: 10.7748/ns2008.02.22.24.35.c64I3.

4. Waleem SSU, Khan YS, Tarar HM. Major Flaws in Technique of
Intramuscular Injections. Pak Armed Forces Med J (PAFMJ) 20 I 3;63(2).

5. Treadwell T. Diagnostic dilemma: intramuscular injection site injuries masquerading as pressure ulcers. Wounds 2003; I5(I0):302-12.

6. Yuan J, Liu Y, Yang Z, Cai Y, Deng Z, Qin P, et al. Mycobacterium abscess. Post injection abscesses from extrinsic contamination of multiple dose bottles of normal saline in a rural clinic. Int J Infect Dis. 2009; I 3(5):53742. DOI: I0. I0I6/j.ijid.2008.II.024.

7. Ebright JR, Pieper B. Soft tissue infections in injection drug users. Infect Dis Clin North Am 2002; I6(3):697-7I2. DOI: |0.1016/S089|-5520(02)000I7-X.

8. Akbar Z, Nizami K, Ahmad F, Alam M. Incidence and aetiology of intramuscular injection abscess. Pak J Med Health Sci 20 I4;8(3):720-22.

9. McGarvey M, Hooper AC. The deltoid intramuscular injection site in the adult. Current practice among general practitioners and practice nurses. Ir Med J 2005;98(4): I 05-7.

10. Devi DR, Indumathi VA, Indira S, Babu PR, Sridharan D, Belwadi MR.. Injection site abscess due to Mycobacterium fortuitum: a case report. Indian J Med Microbiol 2003;2।(2): I33-4. 
I I. Harsch IA, Pietzcker T, Wiest GH, Hahn EG, Ficker JH. Recurrent gluteal injection abscesses as a complication of frequent intramuscular self-injection. Med Klin 200 I;96(5): 298-9.

12. Beecroft PC, Redick S. Possible complications of intramuscular injections in the pediatric unit. Pediatr Nurs 1989;15(4):333-6.
I3. Wynaden D, Landsborough I, McGowan S, Baigmohamad Z, Finn M, Pennebaker D. Best practice guidelines for the administration of intramuscular injections in the mental health setting. Int J Ment Health Nurs 2006; 15: 195-200. DOI: 10.1III/j. | 447-0349.2006.00423.x.

14. Afridi SP, Memon A, Alam SN.
Recurrent abscesses following an intramuscular injection of diclofenac sodium. J Surg Pak 201 I ; I6(2):82-4.

15. Simonsen L, Kane A, Lloyd J, Zaffran $M$, Kane M. Unsafe injections in the developing world and transmission of bloodborne pathogens: a review. Bull World Health Organ 1999;77(10):789-800.

\section{AUTHORS' CONTRIBUTIONS}

Following authors have made substantial contributions to the manuscript as under:

MA: Concept \& study design, acquisition of data, final approval of the version to be published.

MA \& IA: Drafting the manuscript, critical review, final approval of the version to be published.

SH: Analysis and interpretation of data, drafting the manuscript, final approval of the version to be published.

Fakhar-e-Alam: Acquisition of data, drafting the manuscript, final approval of the version to be published.

Authors agree to be accountable for all aspects of the work in ensuring that questions related to the accuracy or integrity of any part of the work are appropriately investigated and resolved. 